\title{
Influence of local vibration on plasma creatine phosphokinase (CPK) activity
}

\author{
A OKADA, H OKUDA, R INABA, AND M ARIIZUMI
}

From the Department of Public Health, School of Medicine, Kanazawa University, Takara-machi 13-1, Kanazawa, 920 Japan

ABSTRACT This study was designed to obtain basic information about the mechanism of the occurrence of muscular disorders after exposure to vibration. The hind legs of rats were exposed to acute and chronic local vibration at frequencies of $30,60,120,240,480$, and $960 \mathrm{~Hz}$ with a constant acceleration of $50 \mathrm{~m} / \mathrm{sec}^{2}$. The exposure time was four hours for acute, and four hours a day for two weeks continuously for chronic exposure. Blood was collected after exposure to measure plasma creatine phosphokinase (CPK) activity. In both exposure groups the activity of plasma CPK was significantly higher at $30,60,120,240$, and $480 \mathrm{~Hz}$ compared with the control group and was especially high at $30 \mathrm{~Hz}$; there was no significant change at $960 \mathrm{~Hz}$. As a result of an analysis of the CPK isoenzymes, the increase in plasma CPK activity was shown to be due to the activity of the plasma CPK-MM fraction, originating in the skeletal muscle. Plasma CPK activity showed a tendency to decrease gradually with the increase in vibration frequency during acute exposure but showed no such tendency during chronic exposure. There was no remarkable pathohistological change in muscle preparations from the hind legs, hence it was presumed that the increase in plasma CPK activity was caused not by the morphological changes of muscle but by other mechanisms, suche as an increase in the permeability of the cell membrane.

The hazards to operators using vibrating tools such as chain saws or rock drills are caused by hand-arm transmitted vibration. The typical symptoms are based on disorders of the peripheral circulation, the peripheral nerves and the musculoskeletal system. Concerning the disorders of muscle, it is controversial whether the disorders arise from vibration itself or from other causes related to the working conditions. Although some epidemiological studies relating to this problem have been reported, ${ }^{12}$ there have been few experimental studies. Considering vibration as a physical stress, it is important to take account of the intensity and frequency of vibration. The vibrations from vibrating tools are composed of different frequencies so that it seems useful to indicate which frequency has a serious effect on muscle function in order to help elucidate the mechanism by which the disorders are caused.

The purpose of the present study was to obtain some basic information about the mechanism of the

Received 30 August 1984

Accepted 12 March 1985 occurrence of muscle disorders that are caused by exposure to local vibration.

\section{Material and methods}

MATERIALS

For acute local vibration exposure experiments, the animals used were 35 male Wistar strain rats weighing 246-302 g; for chronic vibration exposure experiments, 33 male rats of the same strain were used.

\section{EXPOSURE TO VIBRATION}

The apparatus used to produce vibration was composed of an electromagnetic shaker (EMIC 513-A, shaking power $7.5 \mathrm{~kg}$; vibration frequency range 5-5000 Hz) coupled to an amplifier (TACHIKAWA TA-100), a function oscillator (TORIO AG202), and a vibration meter (EMIC 505-D).

The animals were placed in individual wire mesh cages, in the prone position. The hind legs were outside the case and the plantar surfaces were horizontally fixed to the vibrating plate by means of double sided adhesive tapes so that the vibration would be transmitted only to the hind legs. The part of the cage 
containing the rest of the rat was fixed on a nonvibrating plate separated from the shaker. The hind limbs were exposed to vertical sinusoidal vibration with frequencies of $30,60,120,240,480$, and $960 \mathrm{~Hz}$ under a constant acceleration of $50 \mathrm{~m} / \mathrm{sec}^{2}$. The duration of exposure was four hours in the acute experiments, and four hours a day for two weeks in the chronic exposure experiments.

Before the experiments the rats were trained for one week to ride on the vibrating platform.

The control group for each experiment was placed in wire mesh cages like the exposed group and the cages were placed near to the operating electromagnetic shaker during the exposure experiment, so that any noise effect would still be experienced.

\section{BLOOD COLLECTION}

Shortly after the exposure in the acute experiment, and 24 hours after the last exposure in the chronic experiment, pentobarbital $(0.8 \mathrm{mg} / \mathrm{kg}$ weight $)$ was intraperitoneally injected into the rats and arterial blood was drawn from the abdominal aorta by means of heparinised syringe under anaesthesia. The collected blood was centrifuged for 20 minutes at 2000 rpm and the plasma was separated.

ASSAY OF PLASMA CREATINE PHOSPHOKINASE (CPK) ACTIVITY

The plasma total-CPK(t-CPK) and its isoenzyme, plasma CPK-MM fraction, were separated using a CPK assay kit (Worthington Biochemical Corporation, USA) and their activities were determined using a spectrophotometer (Shimazu UV 202 type). Each enzyme activity was determined within 12 hours of collecting the blood samples.

\section{PATHOHISTOLOGICAL OBSERVATION}

Pathohistological preparations of muscles from the hind legs were made from the chronically exposed groups $(30,60$, and $240 \mathrm{~Hz})$ and the controls, stained with hematoxylin and eosin, and examined with a light microscope.

\section{Results}

\section{ACUTE LOCAL VIBRATION EXPOSURE}

Figure 1 shows the values of plasma t-CPK activity at each vibration frequency, expressed as the mean \pm SD. The values for the plasma t-CPK activity in the exposed groups were $482.4 \pm 62.4 \mathrm{IU} / 1$ at $30 \mathrm{~Hz}$, $249.0 \pm 82.5 \mathrm{IU} / 1$ at $60 \mathrm{~Hz}, 232.4 \pm 53.8 \mathrm{IU} / 1$ at 120 $\mathrm{Hz}$, and $141.9 \pm 28.9 \mathrm{IU} / \mathrm{l}$ at $240 \mathrm{~Hz}$. Compared with the value in the control group (33.1 $\pm 14 \cdot 2 \mathrm{IU} / \mathrm{l})$ each of those in the exposed groups was significantly high $(p<0.001)$. The value at $480 \mathrm{~Hz}(86.9 \pm 22.4 \mathrm{IU} / \mathrm{l})$ was also shown as high by comparison with the con-

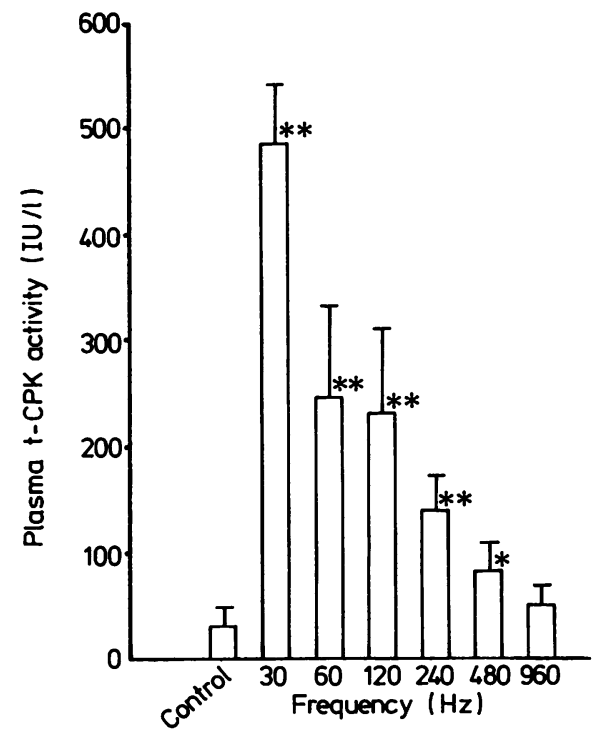

Fig 1 Effects of different vibration frequencies on total plasma creatine phosphokinase ( $t$-CPK) activity (mean $\pm S D)$ in five rats. ${ }^{*} p<0.01,{ }^{* *} p<0.001$.

trol $(\mathrm{p}<0.01)$. The value at $960 \mathrm{~Hz}$ was $51.2 \pm 16.4$ $\mathrm{IU} / \mathrm{l}$ and was not significantly different from the control value.

Figure 2 shows the values for the plasma CPK-MM fraction activity at each vibration frequency; the figures are expressed as the mean \pm SD. The values

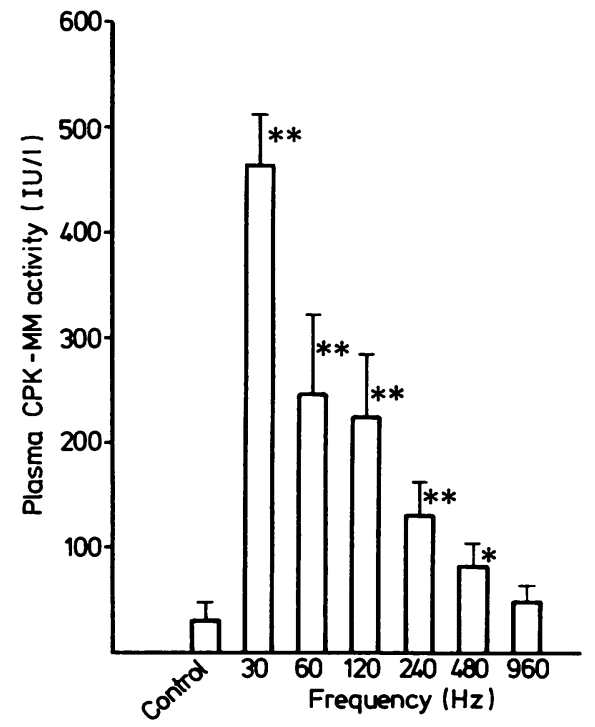

Fig 2 Effects of different vibration frequencies on plasma $C P K-$ muscle muscle (CPK-MM) fraction activity (mean $\pm S D)$ in five rats. ${ }^{*} p<0.01,{ }^{* *} p<0.001$. 
were $467 \pm 50 \cdot 2 \mathrm{IU} / 1$ at $30 \mathrm{~Hz}, 243 \cdot 1 \pm 81 \cdot 2 \mathrm{IU} / 1$ at $60 \mathrm{~Hz}, 228.5 \pm 53.9 \mathrm{IU} / \mathrm{l}$ at $120 \mathrm{~Hz}$, and $136.4 \pm 29.3$ IU $/ 1$ at $240 \mathrm{~Hz}$. Compared with the control value $(31.6$ $\pm 13.6 \mathrm{IU} / \mathrm{l})$ each of the exposed levels was significantly high $(\mathrm{p}<0.001)$. The value at $960 \mathrm{~Hz}$ was not significantly different from the control value.

\section{CHRONIC LOCAL VIBRATION EXPOSURE}

Figure 3 shows the values of plasma t-CPK activity for each vibration frequency, which are expressed as the mean \pm SD. The plasma $\mathrm{t}-\mathrm{CPK}$ activities of the exposed group were $430.0 \pm 41.9 \mathrm{IU} / 1$ at a vibration frequency of $30 \mathrm{~Hz}, 204 \cdot 6 \pm 35 \cdot 2 \mathrm{IU} / 1$ at $60 \mathrm{~Hz}, 181 \cdot 0$ $\pm 38.4 \mathrm{IU} / 1$ at $120 \mathrm{~Hz}, 186.1 \pm 38.4 \mathrm{IU} / 1$ at $240 \mathrm{~Hz}$, and $249.5 \pm 82.5 \mathrm{IU} / \mathrm{l}$ at $480 \mathrm{~Hz}$. Compared with the value of the control group (93.8 $\pm 8.5 \mathrm{IU} / \mathrm{l})$ each of these was significantly high $(\mathrm{p}<0.001)$. The plasma t-CPK activity at $960 \mathrm{~Hz}(106.7 \pm 34.4 \mathrm{IU} / \mathrm{l})$ was not significantly different from the control, however.

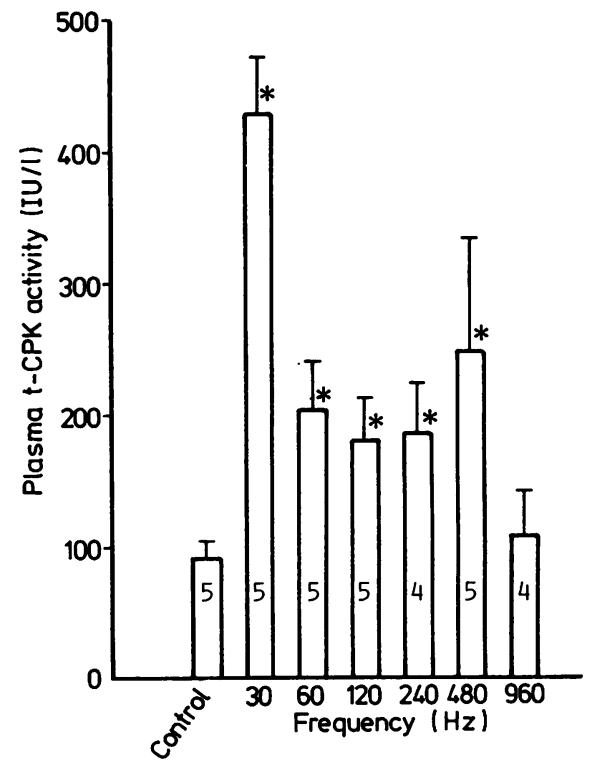

Fig 3 Effects of different vibration frequencies on plasma $t$-CPK activity (mean $\pm S D$ ). Figure in parentheses indicate number of rats. ${ }^{*} p<0.001$.

Figure 4 shows the values of the activity of the plasma CPK-MM fraction for each vibration frequency (mean $\pm \mathrm{SD}$ ). The values were $422.4 \pm 42.5$ IU/l at $30 \mathrm{~Hz}, 198 \cdot 2 \pm 35 \cdot 2 \mathrm{IU} / 1$ at $60 \mathrm{~Hz}, 175 \cdot 2 \pm$ $29.4 \mathrm{IU} / 1$ at $120 \mathrm{~Hz}, 178.8 \pm 30.0 \mathrm{IU} / 1$ at $240 \mathrm{~Hz}$, and $240.8 \pm 76.4 \mathrm{IU} / 1$ at $480 \mathrm{~Hz}$. Each value was significantly higher than that of the control group $(86.5 \pm 7.8 \mathrm{IU} / \mathrm{l})(\mathrm{p}<0.001)$. The CPK-MM fraction activity at $960 \mathrm{~Hz}$ was $98.9 \pm 34.1 \mathrm{IU} / \mathrm{l}$ and this was not significantly different from the control value.

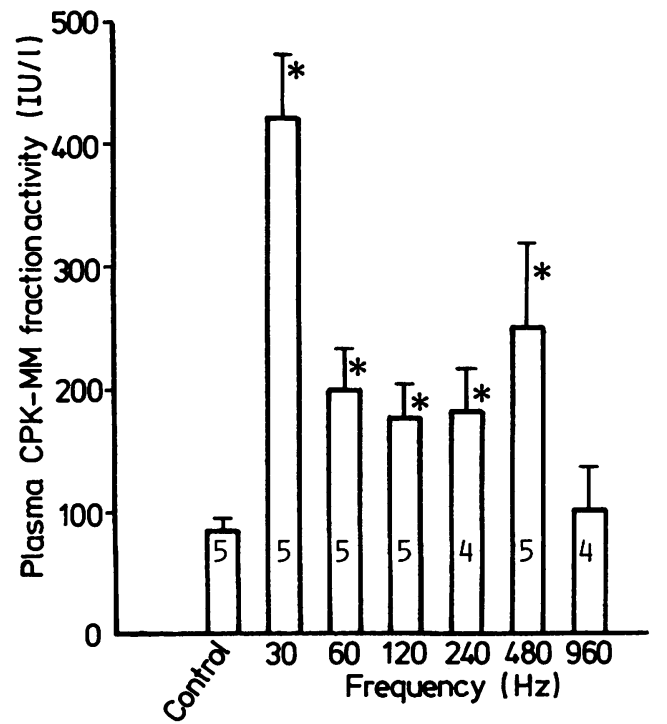

Fig 4 Effects of different vibration frequencies on plasma $C P K-M M$ fraction activity (mean $\pm S D$ ). Figures in parentheses indicate number of rats. ${ }^{*} p<0.001$.

Concerned with the microscopic examination of the preparations from the hind legs, no pronounce pathohistological difference was observed between the control and the group chronically exposed to vio bration. The pathohistological pictures of the planta? ris muscle exposed $(30 \mathrm{~Hz})$ and the control groups are shown in fig 5.

\section{Discussion}

There have been many reports ${ }^{3-7}$ of the disorders of muscle, bone, or joint systems caused by using vibration tools since Holzman's original observations in 1929. ${ }^{8}$ Although some general research on these muscle disorders has been undertaken, ${ }^{7}$ there is little information as to the mechanism by which they are caused.

The present study was designed to investigate the influence of local vibration on muscle function. We focused on CPK which is abundant in the skeletal muscle, and tried to clarify whether or not the activity of this enzyme is affected by vibration and to estimate which vibration frequency is most effective at in- of ducing muscle disorders. The plasma t-CPK activity $N$ showed significantly high values at $30,60,120,240$, N and $480 \mathrm{~Hz}$ compared with the control with both acute and chronic exposure to local vibration. The increase in plasma t-CPK activity was found to be due to that of the plasma CPK-MM fraction which originated in the skeletal muscle. At frequencies of 30,60, 7 

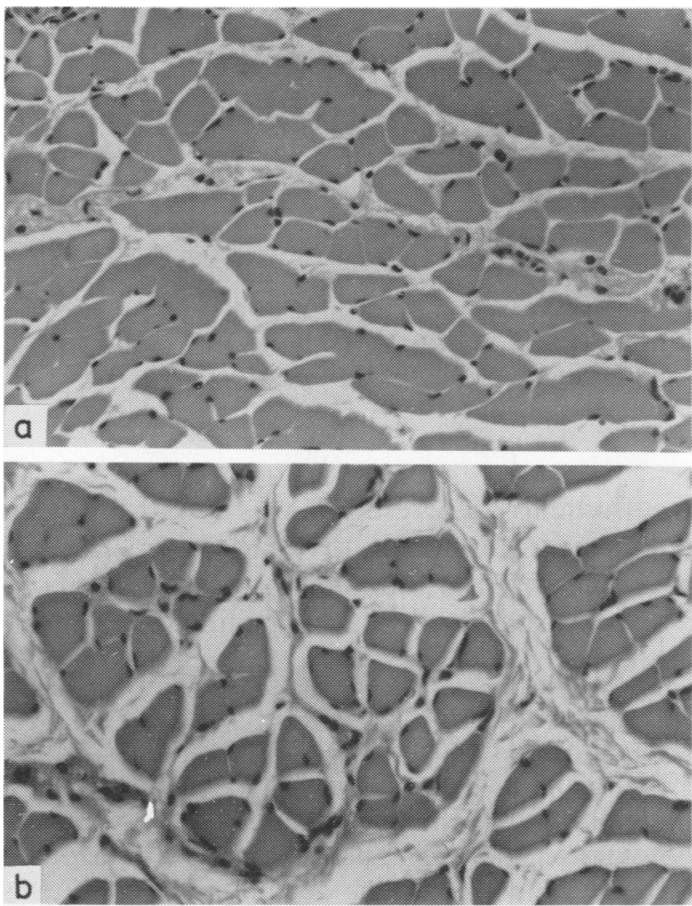

Fig 5 Histological pictures of plantaris muscles (a) control rat and (b) rat exposed to chronic vibration. (Hematoxylin and eosin $\times 400$.)

120,240 , and $480 \mathrm{~Hz}$, a definite increase in plasma CPK activity was observed with both acute and chronic exposure. The highest activity was found at 30 $\mathrm{Hz}$ with both types of exposure. Another point of interest was that, with acute exposure, the increase in plasma t-CPK activity showed a tendency gradually to decrease with the increase of vibration frequency. With chronic exposure, no such tendency was observed. At $480 \mathrm{~Hz}$ the responses of acute exposure and chronic exposure were remarkably different. Thus we were interested to consider the effects of local vibration on plasma CPK activity.

The activity of sarcoplasmic enzymes is increased in various sarcoplasmic diseases such as progressive muscular dystrophy and polymyositis, and in other diseases including myocardial infarction. Some reports have also commented on the changes in sarco- plasmic enzymes in relation to exercise ${ }^{910}$ or heat stress. ${ }^{11}$ By contrast, there have been few reports concerned with the influence of vibration on sarcoplasmic enzymes. It is of considerable practical significance that an increase in CPK activity was found to be induced by vibration and that characteristic changes in CPK activity were noted with different vibration in the present experiment.

Two possibilities may be considered with respect to the increase in CPK activity; the effusion of CPK from the sarcoplasma into the plasma caused by muscular tissue destruction and a rise in the permeability of the muscle cell membrane due to local vibration. In the present experiment pathohistological investigation of the hind legs of rats subjected to the vibration showed no structural changes suggesting muscular tissue destruction. Therefore, presumably, the increase in plasma CPK activity induced by local vibration is attributable to a rise in the permeability of the muscle cell membrane.

\section{References}

${ }^{1}$ Kasamatsu T, Ito N, Iwata $\mathrm{H}$. Biochemical changes in serum constituents in workers operating chain saws. Wakayama Medical Reports 1979;22:53-60.

${ }^{2}$ Takahashi K, Uchikubo S, Oimomi H, Shinko T. Creatine phosphokinase isoenzymes of human heart muscle and skeletal muscle. Clin Chim Acta 1970;38:285-90.

${ }^{3}$ Hellström B, Myhre KA. Comparison of diagnosing Raynaud phenomena of occupational origin. Br J Ind Med 1971;28:272-9.

${ }^{4} \mathrm{Kumlin}$ T, Wiikeri D, Sumari P. Radiological changes in carpal and metacarpal bones and phalanges caused by chain saw vibration. $\mathrm{Br} J$ Ind Med 1973;30:71-3.

${ }^{5}$ Karjalainen P, Alhave EM, Valtola J. Thenar muscle blood flow and bone mineral in the forearms of lumberjacks. $\mathrm{Br} J$ Ind Med 1975;32:11-5.

${ }^{6}$ Volte H. Gelenkschädigung im Hand-Arm Skeletsystem beit Waldarbeitern. Internationales Archiv für Gewerbepathologie und Gewerbehygiene 1967;24:121-6.

${ }^{7}$ Iwata $H$. Comparative studies on vibration disease among chain saw, rivet gun, piston-operated tool and rotating tool operators. Nippon Saigai Igakkai Kaishi 1977;25:184-92.

${ }^{8}$ Holzman F. Erkrankungen durch Arbeiten mit Preßluft-werzeugen. Umschau 1929;33:1002.

${ }^{9}$ Hunter JB, Critz JB. Effect of training on plasma enzyme levels in man. J Appl Physiol 1971;31:20-3.

${ }^{10}$ Ahlborg B, Brohult J. Immediate and delayed metabolic reactions in well-trained subjects after prolonged physical exercise. Acta Med Scand 1967;182:41-54.

${ }^{11}$ Motohashi Y, Miyazaki Y, Takano T, Noziri T, Sekine H. Effects of firefighters of exercise in a hot environment when wearing the antifire coat. Nippon Eiseigaku Zasshi 1983;38:589-97. 